\title{
Preoperative platelet-lymphocyte ratio is an independent prognostic factor in ampullary carcinoma following pancreaticoduodenectomy
}

\author{
WENQIN WANG, WEI LIU, NING ZHANG and XIAODONG HE \\ Department of General Surgery, Peking Union Medical College Hospital, \\ Chinese Academy of Medical Sciences Peking Union Medical College, Beijing 100730, P.R. China
}

Received October 7, 2017; Accepted June 18, 2018

DOI: $10.3892 / 01.2018 .9285$

\begin{abstract}
The objective of the present study was to evaluate whether preoperative platelet-lymphocyte ratio (PLR) and neutrophil-lymphocyte ratio (NLR) could predict the prognosis for curative resected ampullary carcinoma. A total of 94 patients were retrospectively included over a 6-year period in which consecutive cases underwent pancreaticoduodenectomy for ampullary malignancy. Preoperative blood results were available in the 94 cases of resected ampullary carcinoma. Preoperative PLR and NLR cut-off values of 226.8 and 2.58 were determined to represent the optimal cut-off values in the cases for survival analysis. PLR remained a significant independent predictor of survival in multivariate analysis (Cox, $\mathrm{P}<0.001)$ in addition to tumor differentiation $(\mathrm{P}<0.001)$, nodal status $(\mathrm{P}<0.001)$ and stage $(\mathrm{P}<0.001)$. While NLR failed to serve as a prognostic factor in univariate $(\mathrm{P}=0.0637)$ and multivariate $(\mathrm{P}=0.164)$ survival analysis. Furthermore, the nodal involvement rate was higher in high PLR group (74.2 vs. $19.05 \%, \mathrm{P}<0.001)$. Preoperative PLR and NLR merit further evaluation as a prognostic index in curative resected ampullary carcinoma. Additionally, it is a candidate predictor for the lymph node metastasis.
\end{abstract}

\section{Introduction}

Ampullary carcinoma is a rare histological type of gastrointestinal (GI) malignancies accounting for approximately $0.2-0.5 \%$ worldwide $(1,2)$. The radical and beneficial

Correspondence to: Dr Xiaodong He, Department of General Surgery, Peking Union Medical College Hospital, Chinese Academy of Medical Sciences Peking Union Medical College, 1 Shuaifuyuan Wangfujing, Beijing 100730, P.R. China

E-mail: hexdpumch@sina.com

Key words: ampullary carcinoma, pancreatoduodenectomy, prognosis, platelet-lymphocyte ratio, neutrophil-lymphocyte ratio, lymph node metastasis surgery is pancreatoduodenectomy for resectable ampullary malignancies $(3,4)$.

Carbohydrate antigen 19-9 (CA19-9) and bilirubin are well-established preoperative markers for indicting the prognosis of ampullary carcinoma (5-7). However, they exhibit unreliable and inconsonant characteristics in different studies with different patient cohorts $(8,9)$. The critical disadvantages of CA19-9 and bilirubin are the deterioration in low sensitivity and specificity in jaundiced patients (9-11) and the ball-valve effects, as elevated CA19-9 and bilirubin associated with ampullary lesions can be intermittent) (1).

Therefore, simple, easily available and credible biomarkers for prognosis for patients with ampullary carcinoma are needed (12). Systematic inflammatory response (SIR) has been proven to be closely associated with cancer initiation, promotion, malignant conversion, invasion and metastasis (13-16). Several inflammatory biomarkers are routinely available from the pre-treatment routine blood test, including platelet count, platelet to lymphocyte ratio (PLR) and neutrophil to lymphocyte ratio (NLR). PLR and NLR have been the most frequently inflammatory biomarkers used to assess the prognosis in a number of different types of cancer $(7,17,18)$, including ovarian cancer. Nevertheless, only one previous article has explored PLR as prognostic factor in ampullary carcinoma (7), and, to the best of our knowledge, there are no studies regarding NLR. Therefore, it is necessary to provide more evidence regarding the prognostic role of PLR and NLR in ampullary carcinoma.

Therefore, an aim of the present study was to determine whether preoperative PLR and NLR are preoperative predictive indicators for patients with ampullary carcinoma following curative surgery, then providing additional evidence to for physicians to make an improved clinical decision prior to surgery and theoretically helping to identify tumor progression.

\section{Materials and methods}

A total of 94 complete ampullary carcinoma (AC) cases who received surgery were included in the present study and diagnosed with AC by pathology. Retrospective data were extracted from the consecutive 94 patients (50 males and 44 females; median age 62 years; age range, $39-82$ years) undergoing pylorus-preserving pancreaticoduodenectomy 
(PPPD) or classical Kausch-Whipple (Whipple) resection between January 2010 and September 2016 at the Peking Union Medical University Hospital (Beijing, China). The cases were excluded if: i) The patient succumbed within 30 days after surgery; ii) there was incomplete information; iii) the cancer was mixed type; iv) the patient received non-radical surgery; v) the patient succumbed during follow-up. Patient demographics, operative details, and the histological characteristics of the resected specimen were all extracted and numbered as Patient ID, due to no personal information being collected. A positive resection margin (R1) was defined as tumor involvement of margin under microscopic examination without any involvement in physical examination. While, R2 was defined as tumor involvement of the margin under microscopic examination, as well as involvement in physical examination No R2 resections were identified. Details of preoperative biliary drainage and adjuvant therapy were also collected, and survival data were obtained. The preoperative full blood count, CA19-9, and concurrent bilirubin levels were recorded where available. The normal diagnostic reference interval for serum CA19-9 was based on the previous study and our laboratory specification. For pre-operative CA19-9 a cut-off value of $>150 \mathrm{kU} / \mathrm{l}$ was used to define the high-risk group for CA19-9 when recorded in the absence of concurrent cholestasis, such as bilirubin $\leq 35 \mu \mathrm{mol} / 1$, and a cut-off value of $>300 \mathrm{kU} / 1$ was used in the presence of cholestasis, such as bilirubin $>35 \mu \mathrm{mol} / 1$. For pre-operative CA19-9 a cut-off value of $>255.5 \mathrm{kU} / \mathrm{l}$ was used $(19,20)$.

Additionally, the PLR optimum cut-off point 226.8 was determined represent the optimum stratification point at which the survival differences between two groups was maximized. The pathological stage of the ampullary carcinoma was based on the update 8th edition of American Joint Committee On Cancer (AJCC) (21) by two pathologists independently who were blind to the study. The pathological report was offered and authorized by the Affiliated Pathology Department of Peking Union Medical College Hospital, Chinese Academy of Medical Sciences and Peking Union Medical College (Beijing, China).

Statistical analysis. Continuous data were described and present as the median \pm interquartile range (IQR) or $95 \%$ confidence intervals (CI). Relationships between the two continuous variables were analyzed using Spearman's rank correlation. Comparative analysis of categorical data was based on $\chi^{2}$ or Fisher's exact tests. Survival data were analyzed using log rank testing for univariate analysis and Cox proportional hazards with forward-stepwise regression for multivariate analysis. Survival analysis by the continuous variable was categorized by the optimum cut-off of baseline platelet/netrophil to lymphocyte ratio value, which were defined by maximally selected Log-rank statistics $(22,23)$. Patients who died within 30 days after surgery were excluded from survival analysis. $\mathrm{P}<0.05$ was considered to indicate a statistically significant difference. Statistical analysis was performed using R software version 3.4.0 for Windows (GUI front-end), Graph Pad Prism 7.00 (GraphPad Software, Inc., La Jolla, CA, USA) and IBM SPSS Statistics 20 for Windows (IBM Corp., Armonk, NY, USA).
Table I. Demographics along with the preoperative CA19-9 and full blood count results of Ampullary carcinoma cases who received pancreaticoduodenectomy.

\begin{tabular}{|c|c|}
\hline Demographics & Number \\
\hline No. of patients identified & 94 \\
\hline Male/female & $50: 44$ \\
\hline Median age (IQR) & $62(54-68)$ years \\
\hline $\begin{array}{l}\text { Overall median survival } \\
\text { time }(95 \% \mathrm{CI})\end{array}$ & $\begin{array}{c}48 \text { (39.7-56.3) } \\
\text { months }\end{array}$ \\
\hline \multicolumn{2}{|l|}{ Surgery } \\
\hline Whipple & 89 \\
\hline PPPD & 5 \\
\hline \multicolumn{2}{|l|}{$\begin{array}{l}\text { Preoperative intervention } \\
\text { for biliary stenting }\end{array}$} \\
\hline No & 47 \\
\hline Yes & 47 \\
\hline \multicolumn{2}{|l|}{ Adjuvant therapy received } \\
\hline No & 82 \\
\hline Yes & 12 \\
\hline Preoperative CA19-9 results available & 76 \\
\hline Median preoperative & 76.2 \\
\hline CA19-9 (IQR) $)^{\mathrm{a}}$ & (15 to 256$) \mathrm{U} / \mathrm{ml}$ \\
\hline \multicolumn{2}{|l|}{$\begin{array}{l}\text { Number of jaundiced cases } \\
\text { at time of CA19-9 estimation } \\
\text { (bilirubin }>35 \mu \mathrm{mol} / 1 \text { ) }\end{array}$} \\
\hline Jaundice & 51 \\
\hline No jaundice & 45 \\
\hline Preoperative FBC available & 94 \\
\hline Within 7 days & 68 \\
\hline Following 7 days & 26 \\
\hline Median platelet-lymphocyte ratio (IQR) & $\begin{array}{c}152.6 \\
\text { (114.7 to } 229.6)\end{array}$ \\
\hline Neutrophilia present $\left(>7.5 \times 10^{6} / \mathrm{ml}\right)$ & 8 \\
\hline Lymphocytopaenia present $\left(<1.0 \times 10^{6} / \mathrm{ml}\right)$ & 13 \\
\hline Thrombocytosis present $\left(>400 \times 10^{6} / \mathrm{ml}\right)$ & 0 \\
\hline
\end{tabular}

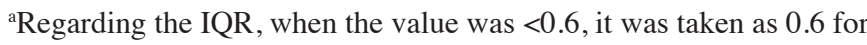
stastastic analysis; the median value may be $<76.2$. IQR, interquartile range; CI, confidence interval; CA19-9, Carbohydrate antigen 19-9. PPPD, pancreaticoduodenectomy; FBC, full blood count.

\section{Results}

Patient clinicopathological features according to preoperative PLR. A total of 345 consecutive patients underwent pancreatoduodenectomy (PPPD and Whipple) for pancreatic or perampullary tumors during the study period. Among them, 97 cases had histologically confirmed carcinoma arising from the ampulla of Vater. A single patient (1.03\% of the patient cohort) who died within 30 days following surgery was excluded from the subsequent survival analyses. Two patients were also excluded for incomplete information. Finally, 94 complete AC cases were included in this study. There were a total of 71 censored cases with a median follow-up time of 21 months 


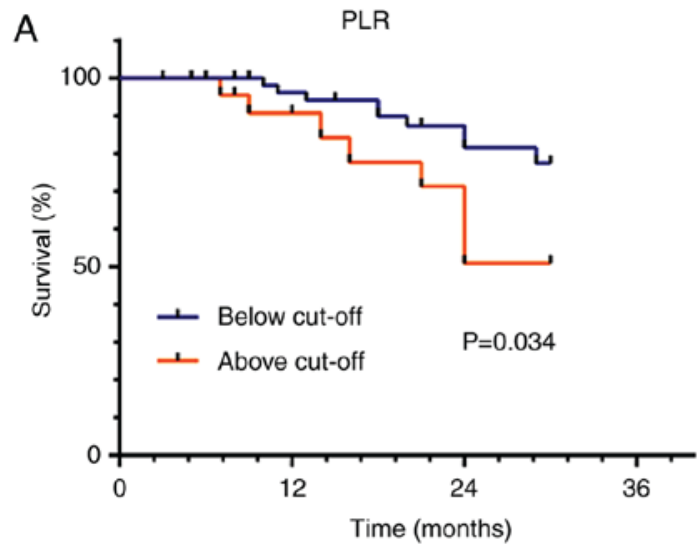

Numbers at risk:

$\begin{array}{lllll}\perp & 66 & 51 & 35 & 19 \\ \perp & 23 & 17 & 12 & 3\end{array}$

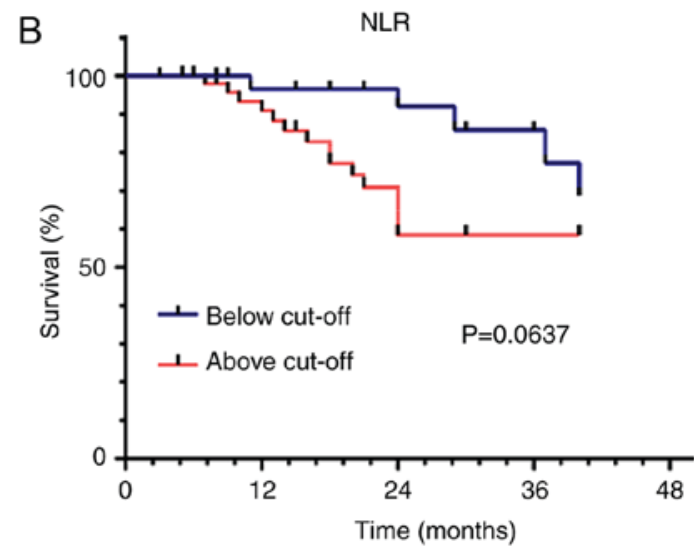

$\begin{array}{lllcc}41 & 49 & 23 & 14 & 9 \\ 49 & 40 & 25 & 9 & 5\end{array}$

Figure 1. (A) Kaplan-Meier cumulative survival curves for ampullary carcinoma patients stratified by PLR $\leq 226.83$; (B) Kaplan-Meier cumulative survival curves for ampullary carcinoma patients stratified by NLR $\leq 2.58$. PLR, preoperative platelet-lymphocyte ratio; NLR, preoperative neutrophil-lymphocyte ratio.

(IQR=12-30 months). Median overall survival time of the study group was 48 months (95\% CI=39.7 to 56.3 months). The demographics of patients in the study along with the preoperative full blood count results were listed in Table I.

Outcomes. The median survival time stratified by preoperative CA19-9 levels (at a cut-off value of $\leq 150$ or $\leq 300 \mathrm{kU} / 1$ in jaundiced cases, the cut-off value of 255.5 for all cases), PLR (at cut-off value $\leq 226.83$ ), NLR (at cut-off value $\leq 2.58$ ) and total bilirubin (Tbil) level (at the cut-off $12.6 \mu \mathrm{mol} / 1$ $/ 211.7 \mu \mathrm{mol} / \mathrm{l}$ ) as well as the other various histological subgroups were shown in Table II.

The corresponding survival curves when stratifying by PLR and NLR are shown in Fig. 1A. No significant associations between CA19-9 and PLR (Spearman, rho=1, P=0.097) or between Tbil and platelet-lymphocyte ratio (Spearman, rho=1, $\mathrm{P}=0.13$ ) were identified. Significant correlation was observed between Tbil and CA19-9 (Spearman, rho=0.487, $\mathrm{P}=0.000$ ), PLR and NLR (spearman, rho=0.727, $\mathrm{P}=0.000$ ); NLR and tbil (Spearman, rho $=0.184, \mathrm{P}=0.077) \mathrm{NLR}$ and CA19-9 (Spearman, rho=0.107, $\mathrm{P}=0.354$ ).

Associations between PLR and pathological characteristics. The correlation between preoperative indices and postoperative histological characteristics using $\chi^{2}$ was listed in Table III. The higher PLR is, the higher proportion of positive lymph node is $(\mathrm{P}<0.01)$. No significances were identified between CA19-9 and nodal status, tumor differentiation or stage. Neither between Tbil or NLR and those characteristics.

Analysis of multiple prognostic factors. The results of a multivariate survival analysis using Cox Log rank proportional hazards with forward stepwise regression are shown in Table IV. In which preoperative indexes including CA19-9, Tbil, PLR and NLR alongside with histological indexes including stage, tumor differentiation and nodal status were presented. Nodal status failed to emerge as a significant variable in forward stepwise regression for it to demonstrate linear dependence with stage, and was therefore omitted from the final multivariate model. The supplementary Cox analysis including nodal status without stage showed that it was also an independent index with Hazard risk (HR) 5.026 (95\% CI 3.937-6.416, $\mathrm{P}<0.001)$. The Cox analysis suggested that all the indexes included were independent prognostic variables in this patient group. The results of a multivariate survival analysis referring to NLR demonstrated NLR was not an independent prognostic index $(\mathrm{P}>0.05)$ (data not shown).

Risk stratification by Tbil and PLR. CA19-9 and PLR risk stratification is less satisfactory for the high-risk group only identified 1cases. Consequently risk stratification by Tbil and PLR was conducted. The high-risk group was defined as when Tbil and PLR values were above the cut-off. Low-risk groups were determined when both of two parameters were below the cut-off. and intermediate-risk group is conformed that either PLR or Tbil was above the cut-off.

Table V demonstrates that the only significant difference among the three risk groups was adjuvant therapy with a trend toward an increased likelihood of adjuvant therapy in the high-risk groups compared with the low-risk group (Fisher's exact, $\mathrm{P}<0.001)$. No significant difference was found in the proportion of patients undergoing preoperative biliary drainage when comparing the three risk groups $(\mathrm{P}=0.650)$. There was no difference in survival when comparing cases who did $(n=12)$ or $\operatorname{did} \operatorname{not}(\mathrm{n}=80)$ receive adjuvant therapy in the whole patient group (median survival were $>60(95 \%$ CI=NR) months and 46, Log rank, $\mathrm{P}=0.0956)$. Similarly, there was no significant difference in the proportion of patients who undergoing preoperative biliary drainage (median survival $>60(95 \% \mathrm{CI}=\mathrm{NR})$ months and $40(95 \% \mathrm{CI}=23.891$ to 56.109$)$ months respectively-Log rank, $\mathrm{P}=0.138)$.

Analysis of risk model using cox regression. Table VI demonstrates that the risk model being an independent predictive value with a hazard ratio 1.78 and 19.973 in intermediate-risk and high-risk group respectively compared with low-risk group $(\mathrm{P}<0.0001)$. Tumor-node-metastasis $(\mathrm{TNM})$ was also 
Table II. Median overall survival times (log rank) according to preoperative CA19-9, Tbil, platelet-lymphocyte ratio and histological hub-groups in the overall study group.

\begin{tabular}{|c|c|c|c|}
\hline Characteristics & Number of patients & Median survival (months) & P-value \\
\hline Preoperative CA19-9 & & & 0.499 \\
\hline Below cut-off & 50 & $48(36.5-59.4)$ & \\
\hline Above cut-off & 26 & $37(33-63)$ & \\
\hline Preoperative CA19-9 & & & $0.01^{\mathrm{a}}$ \\
\hline$\leq 255.5$ & 54 & NR (>60 months) & \\
\hline$>255.5$ & 22 & $37(16.1-57.9)$ & \\
\hline Preoperative PLR & & & 0.255 \\
\hline$\leq 160$ & 49 & $48(40-56)$ & \\
\hline$>160$ & 45 & $40(\mathrm{NR})$ & \\
\hline Preoperative PLR & & & $0.0177^{\mathrm{a}}$ \\
\hline$\leq 226.83$ & 63 & 48 (NR) & \\
\hline$>226.83$ & 31 & $24(\mathrm{NR})$ & \\
\hline Preoperative NLR & & & 0.0637 \\
\hline$\leq 2.58$ & 34 & 46 (NR) & \\
\hline$>2.58$ & 60 & $48(6.938-89.062)$ & \\
\hline Nodal involvement & & & $0.0018^{\mathrm{a}}$ \\
\hline Negative & 59 & NR (66-NR) & \\
\hline Positive & 35 & $33(20.3-45.7)$ & \\
\hline Tumor differentiation & & & $0.0187^{\mathrm{a}}$ \\
\hline Well/moderate & 69 & $48(38.9-57.1)$ & \\
\hline Poor & 25 & $24(12.6-35.4)$ & \\
\hline Stage & & & $0.003^{\mathrm{a}}$ \\
\hline 0 and $\mathrm{I}$ & 32 & NR (30-NR) & \\
\hline II & 27 & 40 (NR-NR) & $(0.0083)$ \\
\hline III and IV & 35 & $46(36.8-55.2)$ & \\
\hline Nerve invasion & & & 0.4176 \\
\hline Positive & 12 & NR (24-NR) & \\
\hline Negative & 82 & $48(38.4-57.6)$ & \\
\hline ICE & & & 0.459 \\
\hline Positive & 20 & NR (33-NR) & \\
\hline Negative & 74 & $37(31.4-42.6)$ & \\
\hline
\end{tabular}

${ }^{a} \mathrm{P}<0.05$. PLR, preoperative platelet-lymphocyte ratio; NLR, preoperative neutrophil-lymphocyte ratio; CA19-9, Carbohydrate antigen 19-9; ICE, intravascular tumor cell thrombus; NR, no statistical results available.

an independent factor in the final cox regression as well $(\mathrm{P}<0.0001)$. While nodal $(\mathrm{df}=0)$ status and CA19-9 $(\mathrm{P}=0.078)$ failed to emerge as significant covariates on forward stepwise regression and was excluded from the final model.

Analysis of predictive prognostic value of PLR and $N L R$ by subgroup analysis. subgroup survival analysis according to PLR and NLR showed PLR was predictive marker in subgroup (male, CA19-9 below-cutoff, jaundice, Mediated/high Differentiation subgroup, rather than other subgroups. While NLR show prognostic value in subgroup (age $\leq 60$ years, CA19-9 above cut-off, jaundice and mediated/high differentiation subgroup) rather than the other subgroups (data not shown). After adjusting for interfering factors related to PLR/NLR and/or probability of tumor recurrence, low NLR patients continued to display a better outcome with bordline difference $(\mathrm{P}=0.0637)$ (Fig. 1B). Particularly, significant differences were shown in postmenopausal patients $(\mathrm{HR}=2.81,95 \% \mathrm{CI} 1.14$ to $6.88, \mathrm{P}=0.0243)$, node negative cancers $(\mathrm{HR}=5.31,95 \% \mathrm{CI} 1.19$ to 23.70 , $\mathrm{P}=0.0292$ ) (data not shown).

\section{Discussion}

The present study identified preoperative PLR as an independent prognostic factor for curative resectable ampullary carcinoma. The results were in agreement with a previous report by Smith et al (7); however, as it was based on a larger 


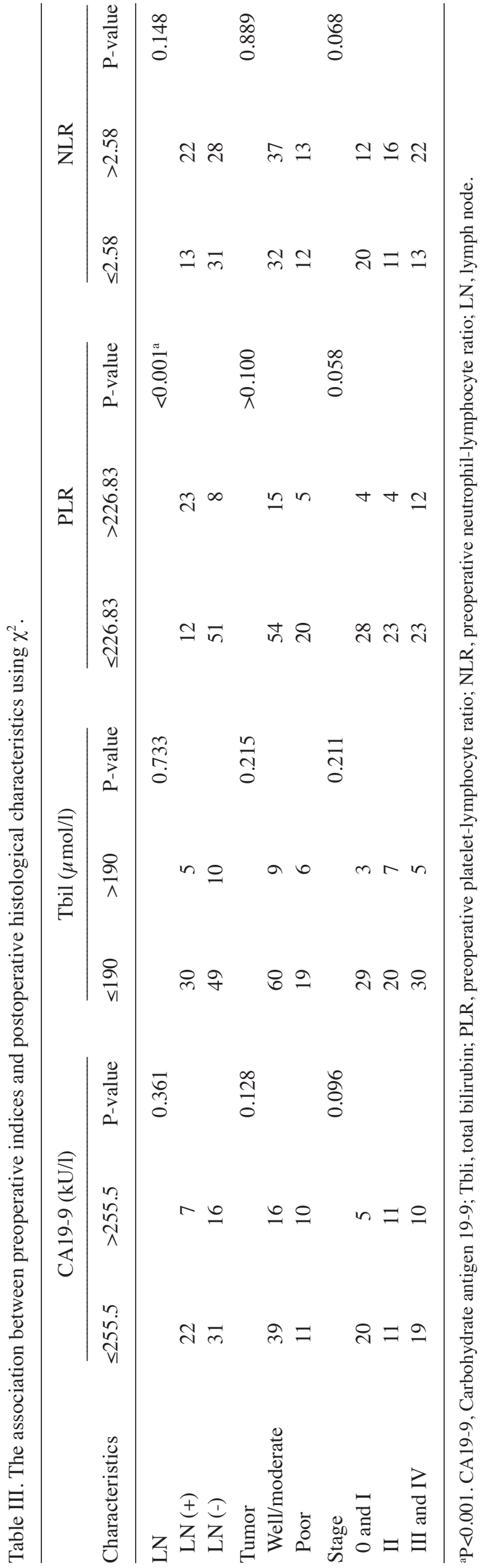

number of cases, the present study contained more detailed analyses, and was performed in accordance with, at the time of analysis, the most up to date AJCC (21). The definition of tumor stage, which was adjusted by evidence-based studies, demonstrated a better guidance for the prognosis in ampullary cancer $(1,21)$. Furthermore, the present study extracted the first examination results of all the preoperative indices to exclude potentially influencing variables, including the preoperative bile drainage. In terms of the optimum cut-off values of CA19-9, bilirubin and PLR, various cut-off values were borrowed from previous ampullary carcinomas and other solid carcinomas studies $(24,25)$. Firstly, the maximally selected log-rank statistics, the statistical analysis designed for the optimum cut-off value of continuous variable based on the Log-rank survival analysis were applied, which was run in $\mathrm{R}$ software (26) (data not shown). To some extent, it contributed to the conclusion that the preoperative PLR was related to the lymph node involvement and prognosis in ampullary cancer following surgical resection.

Furthermore, in the present study, a risk prediction model was established using PLR and Tbil, which demonstrated a good performance in univariate $(\mathrm{P}=0.0004)$ and multivariate $(\mathrm{P}<0.0001)$ survival analysis. While the risk model using PLR and CA19-9 demonstrated a less satisfactory performance with $(\mathrm{P}=0.002)$ and showed dependent predictive value at the expense of all the other predictors $(\mathrm{P}<0.05)$. This maybe partly due to the correlation between the CA19-9 and TNM notwithstanding the border significant difference $(\mathrm{P}=0.053)$ and between PLR and nodal involvement $(\mathrm{P}=0.025)$.

The present study demonstrates for the first time, to the best of our knowledge, the prognostic role of NLR in resectable ampullary cancer and the prognostic value of PLR/ NLR in specific patient subgroups, as the PLR exhibited a prognostic value in a number of specific subgroups, including males, CA19-9 below cutoff, jaundice and mediated/high differentiation subgroups. While NLR exhibited prognostic value in subgroup (age $\leq 60$ years, CA19-9 above cut-off, jaundice, Mediated/high Differentiation subgroup) in spite of border significance in univariate analysis ( $\mathrm{P}=0.0637$; Table II). Previous studies $(27,28)$ have indicated that NLR was a potential independent and significant indicator of a positive outcome in patients with carcinoma of the ampulla of Vater following a pancreaticoduodenectomy. The present study was similar with the conclusions of Haruki et al (27) with a larger study case 94 vs. 37 patients. An additional similar study, with a patient cohort of 87 patients concluded that high NLR had a significantly worse Eastern Cooperative Oncology Group performance score as well as an independent and significant predictive factor of prognosis in patients with ampullary carcinoma (26). However, the present study demonstrated that the predictive roles of NLR for LN metastasis. Two previous meta-analysis regarding the prognostic role of NLR in cancer concluded that a high-pretreatment blood NLR may serve as an adverse prognostic indicator for patients with advanced tumors (29) and predictor of survival in patients with pancreatic cancer (30). However, a previous study reported that a cut-off value of 5 indicated a worst progression free survival (HR 2.23, 95\% CI 1.54-3.23, P=0.019) (29). A latter study included a total of 2,035 patients in 9 cohorts and suggested that an elevated NLR was a predictor of survival in patients with pancreatic 
Table IV. Multivariate (Cox proportional hazards) survival analysis.

\begin{tabular}{|c|c|c|c|c|c|c|}
\hline Characteristics & Coefficient & SE & Wald & HR & $95 \% \mathrm{CI}$ & P-value \\
\hline PLR & 1.099 & 0.144 & 58.412 & 3.001 & $2.264-3.978$ & $<0.001$ \\
\hline Tbil $(\mu \mathrm{mol} / \mathrm{l})$ & & & & & & $<0.001$ \\
\hline $\mathrm{Tb}<17.1$ & - & - & 35.548 & - & - & \\
\hline $\mathrm{Tb}<190$ & 1.634 & 0.279 & 34.310 & 5.125 & $2.966-8.854$ & \\
\hline $\mathrm{Tb} \leq 190$ & 1.446 & 0.351 & 16.985 & 4.245 & $2.134-8.442$ & \\
\hline CA19-9 & 0.416 & 0.137 & 9.185 & 1.516 & $1.158-1.984$ & 0.002 \\
\hline Differentiation & 1.450 & 0.176 & 67.999 & 4.264 & $3.021-6.019$ & $<0.001$ \\
\hline Stage (21) & & & & & & $<0.001$ \\
\hline 0 and $I$ & - & - & - & - & - & \\
\hline II & 1.307 & 0.234 & 31.126 & 3.697 & $2.335-5.852$ & \\
\hline III and IV & 2.416 & 0.217 & 123.429 & 11.200 & $7.313-17.152$ & \\
\hline
\end{tabular}

CI, confidence interval; SE, standard error of regression coefficient; HR, hazard ratio; Tbil, total bilirubin; CA19-9, Carbohydrate antigen 19-9.

Table V. Tumor characteristics according to total bilirubin/platelet-lymphocyte ratio risk stratification.

\begin{tabular}{|c|c|c|c|c|}
\hline Characteristics & High & Intermediate & Low & P-value \\
\hline Lymph node status & & & & 0.206 \\
\hline $\mathrm{LN}(+)$ & 3 & 16 & 16 & \\
\hline $\mathrm{LN}(-)$ & 3 & 18 & 38 & \\
\hline Differentiation & & & & 0.682 \\
\hline Well/moderate & 6 & 21 & 42 & \\
\hline Poor & 2 & 10 & 13 & \\
\hline Resection margin status & & & & 0.058 \\
\hline Positive & 1 & 0 & 0 & \\
\hline Negative & 5 & 30 & 59 & \\
\hline Preoperative biliary stenting & & & & 0.702 \\
\hline No & 2 & 13 & 29 & \\
\hline Yes & 3 & 17 & 27 & \\
\hline Adjuvant therapy received & & & & $<0.01^{\mathrm{a}}$ \\
\hline No & 2 & 26 & 54 & \\
\hline Yes & 4 & 4 & 4 & \\
\hline Stage (21) & & & & 0.086 \\
\hline 0 and $\mathrm{I}$ & 0 & 10 & 22 & \\
\hline II & 3 & 7 & 17 & \\
\hline III and IV & 3 & 14 & 18 & \\
\hline
\end{tabular}

${ }^{a} \mathrm{P}<0.01$. P-value was calculated using Fisher's exact text. LN, lymph node.

cancer without analyzing the cut-off values heterogeneity (28). More large-scale perspective studies, which include a training cohort (the cohort used to calculate the optimum cut-off values as an independent cohort) and validated cohort (a cohort used to validate the efficiency and validity of the optimum cut-off values based on the training cohort) are needed in the future to determine the optimal cut-off values. Additionally, concerning the clinical role of NLR, more detailed studies included the subgroups analysis or propensity score analysis are required to exclude confounding factors.
In 8th AJCC, the assessment of lymph node metastasis was used to predict the prognosis (21). When the OS time was compared according to the lymph node metastasis, the prognostic correlation for patients with N1 (number of metastatic lymph nodes $\geq 1$ ) or N2 (number of metastatic lymph nodes $\geq 4$ ) was not clear (21). In addition, in the present study OS time was compared according to the stage, and tumor differentiation, there were no significant differences between stage 0 and I or between well and moderate differentiation. Furthermore, there were no significant effects of nerve or 
Table VI. Cox regression Tbil/PLR risk stratification and tumor histlogical characteristics.

\begin{tabular}{lcccccc}
\hline Variable & Coefficient (B) & SE & Wald & HR & $95 \%$ CI & P-value \\
\hline Tbil/PLR risk groups & & & & & - & - \\
Low risk & - & - & - & - & - & $<0.001$ \\
Intermediate risk & 0.58 & 0.111 & 27.325 & 1.786 & $1.437-2.220$ & $<0.001$ \\
High risk & 2.993 & 0.352 & 72.395 & 19.973 & $10.006-39.723$ & - \\
Stage (21) & - & - & - & - & - & $<0.001$ \\
0 and I & 1.671 & 0.227 & 54.239 & 5.317 & $3.408-8.295$ & $<0.001$ \\
II & 2.789 & 0.215 & 168.955 & 16.266 & $10.682-24.771$ & \\
II and IV & &
\end{tabular}

SE, standard error of regression coefficient; HR hazard ratio; Tbil, total bilirubin; PLR, preoperative platelet-lymphocyte ratio.

vessel invasion. Following combined and the aforementioned variables were adjusted and, the lymph status, TNM stage and tumor differentiation were demonstrated as independent prognostic indices for the ampullary cancers which were consistent with the AJCC stage based evidences.

In addition, the present study demonstrated that PLR could serve as a predictor for the lymph node (LN) metastasis in the patient cohort of the present study by $\chi^{2}$ test (shown in Table III). LN metastasis is the strongest prognostic predictor for ampullary cancer, while preoperative serum CA19-9 was not associated with the TNM stage, pathologic differentiation or the tumor size (31-33) (shown in Table III), which may serve as an explanation for the prognostic role of PLR.

However, the cut-off values of PLR were not consistent in different study backgrounds. Some studies have reported that a PLR >300 could predict a worse survival in ovarian cancers $(34,35)$, whereas other studies have reported different PLR values from 203 to 299 as prognostic factors in ovarian cancer $(36,37)$. In resectable gastric cancer, higher pre-operative PLR at cut-off 208 showed decreased overall survival time and disease-free survival (24). Another study about advanced pancreatic cancer proved that patients divided by PLR $<200$ vs. $\geq 200$ with 9.1 vs. 4 months overall survival time, respectively (25). In present study, the optimum PLR cut-off value was calculated at 226.83 to predict overall survival following curative surgery.

The critical prognostic role of preoperative PLR in ampullary cancers is well known; however, its mechanism of action has not been completely elucidated in previous studies $(7,38)$. Previous research has demonstrated that tumor cells could increase the peripheral blood platelet count via proinflammatory mediators and other mechanisms such as CA19-9 induced inflammatory molecules (39-43). Meanwhile, these inflammatory factors could also decrease the lymphocyte counts such as IL-6 $(43,44)$. Furthermore, the role of platelets as a negative regulator in immune system has been recently demonstrated, reporting that platelet was the main regulator to decrease the adoptive $\mathrm{T}$ cell count and obliterate its immunologic function in vitro by producing transforming growth factor (TGF)- $\beta$ (45). Therefore, the platelet to lymphocyte ratio could be considered as a relative active inflammation or/and inhibitive immune reaction (46). Platelet count increase has been observed in numerous types of tumors at earlier century and then proved to be a negative predictor in some cancers latterly (47-49). As critical roles in host immune response, lower levels of lymphocytes were associated with a poor prognosis of a variety of tumor types, including breast and colon cancer (50). Therefore, high level of PLR was associated with poor prognosis of many various solid tumors (51). These results have the potential to provide evidence for the antitumor role of the anti-platelet drugs.

Referring to the lymph node metastasis, studies have previously reported that PLR may have the prospective potential to predict nodal involvement in patients with gastric cancer (29), vulvular squamous cell sarcoma (30), and endometrial adenocarcinoma (31). The majority of these demonstrated a higher PLR in nodal involvement group, which was also observed in the present study $(30,31)$; however, a single hemolytic inflammatory index is not a practical guide in clinical use for the accurate predication of lymph node metastasis. Therefore, other studies concerning PLR should include other preoperative indicators such as NLR (29) and contrast-enhanced computerized tomography (52) to establish a model with satisfactory specificity and sensitivity to predict nodal involvement.

Previous studies demonstrated that CA19-9 and bilirubin are independent prognostic factors in present study despite different cut-off values $(5,8)$. Additionally, to the best of our knowledge, there is no existing evidence suggesting that preoperative biliary stenting has an influence on operative mortality or subsequent survival following a pancreaticoduodenectomy (53-55), an adjusted cut-off value of bilirubin to $190 \mu \mathrm{mol} / 1$ (elevated the best cut-off via maximally selected log-rank statistics) was used for the survival benefit of preoperative biliary drainge. Sex showed no significance in univariate survival analysis of median survival time 42 months for males and $>60$ months for females $(\mathrm{P}=0.7746)$. Age with median survival time of 42 months vs. $>60$ months at a cut off 58 years old $(\mathrm{P}=0.1749$ demonstrated no significant impact in the overall survival between the patients with and without preoperative biliary drainage at cut-off $190 \mu \mathrm{mol} / \mathrm{l}$ (data not shown). Similarly, there was no significant difference in survival with and without postoperative adjuvant chemotherapy with a median survival $>60$ vs. 46 months in line with previous studies (56-58). Hence, age, sex, preoperative biliary drainage and adjuvant therapy 
were unlikely to act as a significant confounding factors when interpreting the survival data.

In addition, it is well established that CA19-9 is positively correlated with bilirubin (9-11). Therefore, these two prognostic markers and the PLR alongside with other univariates with statistics significance in Kaplan-Meier analyses were analyzed using Cox Log-rank proportional hazards with forward stepwise regression. Elevated preoperative CA19-9 level, bilirubin level, PLR, poor differentiation, nodal metastases, and advanced stage all exhibited the trend toward poorer survival in univariate and multivariate analysis, which was consistent with the results obtained by previous studies $(6,11)$. Additionally, a previous study demonstrated that preoperative elevated serum CA19-9 (cut-off $36 \mathrm{kU} / \mathrm{l}$ ) and total bilirubin (cut-off $1 \mathrm{mg} / \mathrm{ml}$ ) levels were prognostic factors in ampullary adenocarcinoma and demonstrated an association with the pathological pancreatobiliary type that which proved aggressively invasive, which was closely associated with poor survival (2).

Jaundice was the most common symptom $(50 \%, 47 / 94)$ in the present study, which is similar to previous studies, which accounted for $70-80 \%$ of the chief patient complaint $(59,60)$. The decline in component ratio of jaundice in the present study may be attributed to the advanced economic and medical factors in China. The remaining chief complaints consist of physical discomfort $(15.95 \%, 15 / 94)$ and other atypical digestive system complaints including abdominal pain $34.04 \%$, 32/94). Jaundice is a prognostic factor in univariate Log-Rank analysis compared with a physical discomfort group ( $\mathrm{P}=0.00095,>60$ vs. 40 months). This supports the survival analysis of total bilirubin. So even compared with the atypical digestive symptom ( $\mathrm{P}=0.0034,>60$ vs. 30 months). However there was no significance between the jaundice and other atypical digestive symptoms ( $\mathrm{P}=0.3291,40$ vs. 30 months).

The present study also had some limitations that should not be ignored. Firstly, as a respective study in a single center, all the indexes and pathological were collected from a computerized database, consequently the study cohort may have some unintentional selection bias. Secondly, the optimum cut-off was specifically suitable for the current patients cohort of 94 cases regarding the survival analysis. Finally, the relationship between certain peripheral hematological inflammatory components and the tumor histological items were not assessed in the present study, such as the novel pathological type neuroendocrine tumor. Thus, further large-scale prospective studies are required to verify the results obtained. Furthermore, other specific markers associated with ampullary carcinoma require investigation in future study.

Preoperative PLR and NLR possesses further evaluation as prognostic indices in curative resected ampullary carcinoma. Preoperative PLR is a candidate predictor for lymph node metastasis.

\section{Acknowledgements}

Not applicable.

\section{Funding}

The present study was supported by National Natural Science Foundation of China (grant no. 81372578).

\section{Availability of data and materials}

The datasets used and/or analyzed during the current study are available from the corresponding author on reasonable request.

\section{Author's contributions}

$\mathrm{XH}$ contributed to the conception and design of the study. WL and NZ contributed to the analysis data for the study. WW drafted the study and analyzed the data.

\section{Ethics approval and consent to participate}

The present study was approved by the Ethics Committee of Peking Union Medical College Hospital, and all the participants have included the consent forms.

\section{Patient consent for publication}

All the patients provided consent for publication.

\section{Competing interests}

All the authors declare that they have no conflict of interests.

\section{References}

1. Eeson G, Cleary S, Moulton CAE and Ridgway PF (eds): Ampullary cancer: Springer International Publishing, 2016.

2. Okano K, Oshima M, Yachida S, Kushida Y, Kato K, Kamada H, Wato M, Nishihira T, Fukuda Y, Maeba T, et al: Factors predicting survival and pathological subtype in patients with ampullary adenocarcinoma. J Surg Oncol 110: 56-162, 2014.

3. Tian Y, Wu SD, Chen YS and Chen CC: Transumbilical single-incision laparoscopic cholecystojejunostomy using conventional instruments: The first two cases. J Gastrointest Surg 14: 1429-1433, 2010.

4. Kondo S, Takada T, Miyazaki M, Miyakawa S, Tsukada K, Nagino M, Furuse J, Saito H, Tsuyuguchi T, Yamamoto M, et al: Guidelines for the management of biliary tract and ampullary carcinomas: Surgical treatment. J Hepatobiliary Pancreat Surg 15: 41-54, 2008.

5. Yokoyama N, Shirai Y, Wakai T, Nagakura S, Akazawa K and Hatakeyama K: Jaundice at presentation heralds advanced disease and poor prognosis in patients with ampullary carcinoma. World J Surg 29: 519-523, 2005.

6. Robert PE, Leux C, Ouaissi M, Miguet M, Paye F, Merdrignac A, Delpero JR, Schwarz L, Carrere N, Muscari F, et al: Predictors of long-term survival following resection for ampullary carcinoma: A large retrospective French multicentric study. Pancreas 43: 692-697, 2014.

7. Smith RA, Ghaneh P, Sutton R, Raraty M, Campbell F and Neoptolemos JP: Prognosis of resected ampullary adenocarcinoma by preoperative serum CA19-9 levels and platelet-lymphocyte ratio. J Gastrointest Surg 12: 1422-1428, 2008.

8. Zhao X, Dong J, Huang X, Zhang W and Jiang K: Prognostic factors for survival of patients with ampullary carcinoma after local resection. ANZ J Surg 85: 567-571, 2015.

9. Mann DV, Edwards R, Ho S, Lau WY and Glazer G: Elevated tumour marker CA19-9: Clinical interpretation and influence of obstructive jaundice. Eur J Surg Oncol 26: 474-479, 2000.

10. Ker CG, Chen JS, Lee KT, Sheen PC and Wu CC: Assessment of serum and bile levels of CA19-9 and CA125 in cholangitis and bile duct carcinoma. J Gastroenterol Hepatol 6: 505-508, 1991.

11. Kau SY, Shyr YM, Su CH, Wu CW and Lui WY: Diagnostic and prognostic values of CA 19-9 and CEA in periampullary cancers. J Am Coll Surg 188: 415-420, 1999.

12. Au KK, Josahkian JA, Francis JA, Squire JA and Koti M: Current state of biomarkers in ovarian cancer prognosis. Future Oncol 11: 3187-3195, 2015 . 
13. Zhu L, Li X, Shen Y, Ying C, Fang X, Chen J and Ying Y: A new prognostic score based on the systemic inflammatory response in patients with inoperable non-small-cell lung cancer. Onco Targets Ther 9: 4879-4886, 2016.

14. Namikawa T, Munekage E, Munekage M, Maeda H, Yatabe T, Kitagawa H, Kobayashi M and Hanazaki K: Evaluation of systemic inflammatory response biomarkers in patients receiving chemotherapy for unresectable and recurrent advanced gastric cancer. Oncology 90: 338-326, 2016

15. Dreyer SB, Powell AG, Mcsorley ST, Waterston A, Going JJ, Edwards J, Mcmillan DC and Horgan PG: The pretreatment systemic inflammatory response is an important determinant of poor pathologic response for patients undergoing neoadjuvant therapy for rectal cancer. Ann Surg Oncol 24: 1295-1303, 2017.

16. Geng Y, Qi Q, Sun M, Chen H, Wang P and Chen Z: Prognostic nutritional index predicts survival and correlates with systemic inflammatory response in advanced pancreatic cancer. Eur J Surg Oncol 41: 1508-1514, 2015.

17. Asher V, Lee J, Innamaa A and Bali A: Preoperative platelet lymphocyte ratio as an independent prognostic marker in ovarian cancer. Clin Transl Oncol 13: 499-503, 2011.

18. Zhou X, Xu L, Huang Z, Zhang L, Zhang H, Zhu W and Liu P: The hematologic markers as prognostic factors in patients with resectable gastric cancer. Cancer Biomark 17: 359-367, 2016.

19. Schlieman MG, Ho HS and Bold RJ: Utility of tumor markers in determining resectability of pancreatic cancer. Arch Surg 138: 951-956, 2003

20. Connor S, Bosonnet L, Alexakis N, Raraty M, Ghaneh P, Sutton R and Neoptolemos JP: Serum CA19-9 measurement increases the effectiveness of staging laparoscopy in patients with suspected pancreatic malignancy. Dig Surg 22: 80-85, 2005.

21. Mahul BA, Stephen E, Frederick G, David RB, Robert KB, Mary KW, Jeffrey EG, Carolyn CC, Kenneth RH, Daniel CS, et al: AJCC cancer staging manual. 8th edition. New York. Springer, 2017.

22. Yuan J, Zhou J, Dong Z, Tandon S, Kuk D, Panageas KS, Wong $\mathrm{P}, \mathrm{Wu} \mathrm{X}$, Naidoo J, Page DB, et al: Pretreatment serum VEGF is associated with clinical response and overall survival in advanced melanoma patients treated with ipilimumab. Cancer Immunol Res 2: 127-132, 2014

23. Hothorn T and Lausen B: On the exact distribution of maximally selected rank statistics. Comput Stat Data Anal 43: 121-137, 2003

24. Lian L, Xia YY, Zhou C, Shen XM, Li XL, Han SG, Zheng Y, Mao ZQ, Gong FR, Wu MY, et al: Application of platelet/ lymphocyte and neutrophil/lymphocyte ratios in early diagnosis and prognostic prediction in patients with resectable gastric cancer. Cancer Biomark 15: 899-907, 2015.

25. Martin HL, Ohara K, Kiberu A, Van Hagen T, Davidson A and Khattak MA: Prognostic value of systemic inflammationbased markers in advanced pancreatic cancer. Intern Med J 44: 676-682, 2014

26. Lausen B and Schumacher M: Maximally selected rank statistics. Biometrics 48: 3-85, 1992

27. Haruki K, Shiba H, Horiuchi T, Shirai Y, Iwase R, Fujiwara Y, Furukawa K, Misawa T and Yanaga K: Neutrophil to lymphocyte ratio predicts therapeutic outcome after pancreaticoduodenectomy for carcinoma of the ampulla of vater. Anticancer Res 36: 403-408, 2016.

28. Demirci NS and Erdem GU: Prognostic role of the neutrophil-to-lymphocyte ratio (NLR) in patients with operable ampullary carcinoma. Bosn J Basic Med Sci: Nov 13, 2017 (Epub ahead of print)

29. Mei Z, Shi L, Wang B, Yang J, Xiao Z, Du P, Wang Q and Yang W: Prognostic role of pretreatment blood neutrophil-to-lymphocyte ratio in advanced cancer survivors: A systematic review and meta-analysis of 66 cohort studies. Cancer Treat Rev 58: 1-13, 2017.

30. Cheng H, Long F, Jaiswar M, Yang L, Wang C and Zhou Z: Prognostic role of the neutrophil-to-lymphocyte ratio in pancreatic cancer: A meta-analysis. Sci Rep 5: 11026, 2015.

31. Pang W, Lou N, Jin C, Hu C, Arvine C, Zhu G and Shen X: Combination of preoperative platelet/lymphocyte and neutrophil/lymphocyte rates and tumor-related factors to predict lymph node metastasis in patients with gastric cancer. Eur J Gastroenterol Hepatol 28: 493-502, 2016.

32. Ertas IE, Gungorduk K, Akman L, Ozdemir A, Terek MC, Ozsaran A, Sanci M and Dikmen Y: Can preoperative neutrophil:lymphocyte and platelet:lymphocyte ratios be used as predictive markers for lymph node metastasis in squamous cell carcinoma of the vulva? Eur J Obstet Gynecol Reprod Biol 171: $138-142,2013$
33. Suh DH, Kim HS, Chung HH, Kim JW, Park NH, Song YS and Kang SB: Pre-operative systemic inflammatory response markers in predicting lymph node metastasis in endometrioid endometrial adenocarcinoma. Eur J Obstet Gynecol Reprod Biol 162: 206-210, 2012.

34. Asher V, Lee $\mathrm{J}$ and Bali A: Preoperative serum albumin is an independent prognostic predictor of survival in ovarian cancer. Med Oncol 29: 2005-2009, 2012.

35. Supoken A, Kleebkaow P, Chumworathayi B, Luanratanakorn S and Kietpeerakool C: Elevated preoperative platelet to lymphocyte ratio associated with decreased survival of women with ovarian clear cell carcinoma. Asian Pac J Cancer Prev 15: 10831-10836, 2014.

36. Zhang WW, Liu KJ, Hu GL and Liang WJ: Preoperative platelet/ lymphocyte ratio is a superior prognostic factor compared to other systemic inflammatory response markers in ovarian cancer patients. Tumor Biol 36: 8831-8837, 2015.

37. Nakamura K, Nagasaka T, Nishida T, Haruma T, Ogawa C, Kusumoto T, Seki N and Hiramatsu Y: Neutrophil to lymphocyte ratio in the pre-treatment phase of final-line chemotherapy predicts the outcome of patients with recurrent ovarian cancer. Oncol Lett 11: 3975-3981, 2016.

38. Fan F, Tian Y, Liu S,Zheng G, Zhen L, Xu G, Man G, Xiao L, Fan D and Zhang $\mathrm{H}$ : Combination of PLR, MLR, MWR, and tumor size could significantly increase the prognostic value for gastrointestinal stromal tumors. Medicine (Baltimore) 95: e3248, 2016.

39. Yokoigawa N, Takeuchi N, Toda M, Inoue M, Kaibori M, Yanagida H, Tanaka H, Ogura T, Takada H, Okumura T, et al: Enhanced production of interleukin 6 in peripheral blood monocytes stimulated with mucins secreted into the bloodstream. Clin Cancer Res 11: 6127-6132, 2005.

40. Yokoigawa $\mathrm{N}$, Takeuchi N, Toda $\mathrm{M}$, Inoue $\mathrm{M}$, Kaibori $\mathrm{M}$, Yanagida H, Inaba T, Tanaka H, Ogura T, Takada H, et al: Overproduction of PGE2 in peripheral blood monocytes of gastrointestinal cancer patients with mucins in their bloodstream. Cancer Lett 245: 149-155, 2007.

41. Kannagi R, Izawa M, Koike T, Miyazaki K and Kimura N: Carbohydrate-mediated cell adhesion in cancer metastasis and angiogenesis. Cancer Sci 95: 377-384, 2004.

42. Honn KV, Tang DG and Crissman JD: Platelets and cancer metastasis: A causal relationship? Cancer Metastasis Rev 11: 325-351, 1992.

43. Hussain SP and Harris CC: Inflammation and cancer: An ancient link with novel potentials. Int J Cancer 121: 2373-2380, 2007.

44. Sotomayor EM, Fu YX, Lopezcepero M, Herbert L, Jimenez JJ, Albarracin C and Lopez DM: Role of tumor-derived cytokines on the immune system of mice bearing a mammary adenocarcinoma. II. Down-regulation of macrophage-mediated cytotoxicity by tumor-derived granulocyte-macrophage colony-stimulating factor. J Immunol 147: 2816-2823, 1991

45. Rachidi S, Metelli A, Riesenberg B, Wu BX, Nelson MH, Wallace C, Paulos CM, Rubinstein MP, Garrettmayer E, Hennig M, et al: Platelets subvert T cell immunity against cancer via GARP-TGF $\beta$ axis. Sci Immunol 2: pii: eaai7911, 2017.

46. Kim EY, Lee JW, Yoo HM, Park CH and Song KY: The platelet-to-lymphocyte ratio versus neutrophil-to-lymphocyte ratio: Which is better as a prognostic factor in gastric cancer? Ann Surg Oncol 22: 4363-4370, 2015.

47. Zhang X and Ran Y: Prognostic role of elevated platelet count in patients with lung cancer: A systematic review and meta-analysis. Int J Clin Exp Med 8: 5379-5387, 2015.

48. Ishizuka M, Nagata $\mathrm{H}$, Takagi K, Iwasaki $\mathrm{Y}$ and Kubota $\mathrm{K}$ : Combination of platelet count and neutrophil to lymphocyte ratio is a useful predictor of postoperative survival in patients with colorectal cancer. Br J Cancer 109: 401-407, 2013.

49. O'Byrne KJ, Dobbs N, Propper D, Smith K and Harris AL: Vascular endothelial growth factor platelet counts, and prognosis in renal cancer. Lancet 353: 1494-1495, 1999.

50. Quigley DA and Kristensen V: Predicting prognosis and therapeutic response from interactions between lymphocytes and tumor cells. Mol Oncol 9: 2054-2062,2015.

51. Templeton AJ, Mcnamara MG, Šeruga B, Vera-Badillo FE, Aneja P, Ocaña A, Leibowitz-Amit R, Sonpavde G, Knox JJ, Tran B, et al: Prognostic role of neutrophil-to-lymphocyte ratio in solid tumors: a systematic review and meta-analysis. J Natl Cancer Inst 106: dju124, 2014.

52. Huang C, Jie Y, Li Z, Na L, Zhao J and Qi D: Usefulness of the neutrophil-to-lymphocyte ratio in predicting lymph node metastasis in patients with non-small cell lung cancer. Tumor Biol 36: 7581-7589, 2015 
53. Sewnath ME, Karsten TM, Prins MH, Rauws EJ, Obertop H and Gouma DJ: A meta-analysis on the efficacy of preoperative biliary drainage for tumors causing obstructive jaundice. Ann Surg 236: 17-27, 2002.

54. Povoski SP, Karpeh MS Jr, Conlon KC, Blumgart LH and Brennan MF: Preoperative biliary drainage: Impact on intraoperative bile cultures and infectious morbidity and mortality after pancreaticoduodenectomy. J Gastrointest Surg 3: 496-505, 1999

55. Barauskas G, Urbonas K, Smailyte G, Pranys D, Pundzius J and Gulbinas A: Preoperative endoscopic biliary drainage may negatively impact survival following pancreatoduodenectomy for ampullary cancer. Dig Surg 33: 462-469, 2016.

56. Tank AK, Singh RK, Prakash A, Behari A, Kumar A, Saxena R and Kapoor VK: Adjuvant therapy does not improve survival of ampullary carcinoma patients. Gastrointest Cancer Res (Suppl 1): S31, 2010.

57. Evans DB, Wolff RA and Hess KR: Adjuvant radiotherapy and 5 -fluorouracil after curative resection of cancer of the pancreas and periampullary region. Ann Surg 230: 776-784, 1999.
58. Furuse J, Takada T, Miyazaki M, Miyakawa S, Tsukada K, Nagino M, Kondo S, Saito H, Tsuyuguchi T, Hirata K, et al: Guidelines for chemotherapy of biliary tract and ampullary carcinomas. J Hepatobiliary Pancreat Surg 15: 55-62, 2008 .

59. Yamaguchi K and Enjoji M: Carcinoma of the ampulla of vater. A clinicopathologic study and pathologic staging of 109 cases of carcinoma and 5 cases of adenoma. Cancer 59: 506-515, 1987.

60. Knox RA and Kingston RD: Carcinoma of the ampulla of Vater. Br J Surg 73: 72-73, 1986.

This work is licensed under a Creative Commons Attribution-NonCommercial-NoDerivatives 4.0 International (CC BY-NC-ND 4.0) License. 